ACTA SCIENTIFIC MICROBIOLOGY (ISSN: 2581-3226)

Volume 4 Issue 5 May 2021

\title{
Saccharomyces cerevisiae and Kluyveromyces marxianus: Possibilities and Role of the Most Popular Yeasts in Food Industry
}

\section{Judit Molnár ${ }^{1}$ and Mahendra Pal ${ }^{2 *}$}

${ }^{1} 1$ 1/9 Palánkutca, 9200 Mosonmagyaróvár, Hungary

${ }^{2}$ Narayan Consultancy on Veterinary Public Health and Microbiology, Anand,

Gujarat, India

*Corresponding Author: Mahendra Pal, Professor, Founder Director of Narayan

Consultancy on Veterinary Public Health and Microbiology, Anand, Gujarat, India.
Received: March 15, 2021

Published: April 01, 2021

(C) All rights are reserved by Judit Molnár and

Mahendra Pal.

\begin{abstract}
Fungi are versatile living microbe that has a wide range of uses. Fungi comprised of moulds and yeasts. The yeasts have been recognized to play a significant role in beverage industries. Among the yeasts, Saccharomyces cerevisiae and Kluyveromyces marxianus are the most important representatives. Their utilization is largely determined by their reproductive characteristics, which can also be proved by mathematical relationships, such as generation time and maximum specific rate of growth. They are preferred for use in the food, feed, cosmetics and many other areas. Their advantages are mainly due to their metabolic processes and cell growth, which can be used to produce many well-known products such as single cell protein. In some cases, they can also cause deterioration. It is hoped that Saccharomyces cerevisiae and Kluyveromyces marxianus may be the focus of research interest by demonstrating the importance of the yeast species.
\end{abstract}

Keywords: Fermentation; Industrial Processes; Kluyveromyces marxianus; Saccharomyces cerevisiae; Yeasts

\section{Introduction}

Fungi are eukaryotic, heterotrophic, non-photosynthetic, living organisms that are present in our environment [1]. Many fungi are known to benefit the mankind in a number of ways, such as production of antibiotics, drugs, recombinant vaccines, alcohol, and also land reclamation, bio-control [1]. Fungi occur in yeast and mould form [1]. In our paper, we focus primarily on the yeasts, which have excellent utilization and potential uses. This is manifested primarily in alcoholic fermentation processes, as most of them are facultative anaerobic organisms. These properties are also beneficial for the food, pharmaceutical, feed and cosmetics industries. Due to the metabolic processes of yeasts, in addition to fermentation processes, the production of single cell protein under aerobic con- ditions, the enrichment of certain cosmetic products and animal feeds can also take place.

The most prominent and most widely used species of the yeasts are Saccharomyces cerevisiae and Kluyveromyces marxianus. These two species of the yeasts have become the focus of interest with their role in the industry. Numerous scientific studies proved that fermentation still has areas of a great interest. Since ancient times, it has been one of the fields in science that can always provided new results [2-5]. Our communication focuses on these species in order to present their most important properties and possibilities of their use in food industry, and to summarize the most important research results in connection with these two species of the yeast. 
The most important properties and uses of Saccharomyces cerevisiae

As mentioned earlier, the role of yeasts is significant in many areas. In biochemistry, genetics, cell biology, biotechnology, and many areas of industry, their most researched species is Saccharomyces cerevisiae [6-9]. The enzyme produced by $S$. cerevisiae is $\alpha$-amylase. Due to its enzyme action, it can be used well on highsugar media, such as molasses, sugar solution, and fruits. In addition, it is well utilized and can make excellent use of corn steep liquor solution. The vegetative propagation of $S$. cerevisiae occurs by sprouting, with cells oval [10-12]. Their industrial use is also outstanding due to their ability to utilize sugar, always by a fermentation process suitable for industrial purposes, under aerobic or anaerobic conditions.

\section{Essential properties and uses of Kluyveromyces marxianus}

The role of Kluyveromyces marxianus is gaining increasing importance in industry and science $[13,14]$ as well. The enzyme it produces by $K$. marxianus is $\beta$-galactosidase, which breaks down lactose into galactose and glucose. Therefore, the most useful media for the species are milk-based, but they are also well utilized on a glucose basis. It multiplies rapidly and has excellent sugar breaking ability. Its ethanol production is excellent. With these properties, it has come to the forefront of scientific experiments the most. Vegetative propagation of $K$. marxianus occurs by budding, spores are bean-shaped $[15,16]$.

\section{Metabolic and reproductive characteristics of yeasts}

The growth and product-producing ability of yeasts are the result of metabolic processes in cells. To do this, the yeast cell first absorbs nutrients, which it then uses or converts for growth. The path leading to the breakdown of nutrients is the catabolic process, catabolism. The process required to build a cell is anabolism, which takes place during the regulated functioning of cells. During these metabolic processes, metabolites or transformation products are formed. They are also of great importance for the food, feed industry, and biotechnology.

The use of nutrients is also influenced by the genetic characteristics of the microbial species and environmental conditions. Of the environmental conditions, the presence or absence of oxygen is of paramount importance, as a process contrary to the desired pur- pose can be initiated with or without aeration (ethanol production or yeast growth). In addition, the adjustment of temperature and $\mathrm{pH}$ is also important in fermentation processes, as these parameters affect the life activities of yeasts. The parameters characterizing the growth of the yeasts used in the production of single cell protein can also be interpreted mathematically, so that the cells can be traced the most. Thus, in addition to microbiological measurements, the most important test methods are mathematical models and relationships, including generation time, maximum specific growth rate, and the Monod model. By continuously mapping these parameters, it is possible to refine the experimental processes and set the fermentation parameters, which can also increase the yield of the product.

\section{Conclusion}

The manuscript presents the general characteristics of yeasts and then the most important characteristics of the yeast species $S$. cerevisiae and $K$. marxianus. It also focuses on their potential uses, as these species are used in a number of areas, from the food industry to animal feed, for a variety of purposes, such as single cell protein production, and alcoholic fermentation. Fermentation has been one of the most important biotechnology sectors since ancient times, and it holds surprises and new results for science to this day. By presenting the two yeast species and indicating the latest research findings, we would like to draw attention to their diversity and the latest research findings.

\section{Acknowledgements}

The authors are very thankful to Prof. Dr. R. K. Narayan for his suggestions during the preparation of manuscript and Anubha Priyabandhu for excellent computer help.

\section{Author's Contribution}

All the authors contributed equally. They read the final version and approved it for the publication.

\section{Conflict of Interest}

The authors declare that they do not have conflict of interest.

\section{Source of Financial Grant}

There was no financial support for this manuscript. 


\section{Bibliography}

1. Pal M. "Veterinary and Medical Mycology". First Edition. Indian council of Agricultural Research, New Delhi, India (2007).

2. Galinari É., et al. "Antioxidant, antiproliferative, and immunostimulatory effects of cell wall $\alpha$-D-mannan fractions from Kluyveromyces marxianus". International Journal of Biological Macromolecules 109 (2018): 837-846.

3. López-Domínguez C M., et al. "Enzymatic hydrolysis of Opuntiaficus-indica cladode by Acinetobacter pittii and alcohol fermentation byKluyveromyces marxianus: $\mathrm{pH}$, temperature and microorganism effect”. Biotechnology Reports 24 (2019): 1-6.

4. Amadi O C., et al. "Process optimization for simultaneous production of cellulase, xylanase and ligninase by Saccharomyces cerevisiae SCPW 17 under solid state fermentation using Boksz-Behnken experimental design". Heliyon 6 (2020): 1-12.

5. Hou L., et al. "Selenium-enriched Saccharomyces cerevisiae improves the meat quality of broiler chickens via activation of the glutathione and thioredoxin systems". Poultry Science 99 (2020): 6045-6054.

6. Hong J., et al. "Physicochemical features and microbial community of milk kefir using a potential probiotic Saccharomyces cerevisiae KU200284". Journal of Dairy Science 102 (2019): 10845-10849.

7. Landalta R., et al. "Effective diffusion coefficients and bioconversion rates of inhibitory compounds in flocs of Saccharomyces cerevisiae". Electronic Journal of Biotechnology 42 (2019): $1-5$.

8. Al-Qaisi M., et al. "Effects of a Saccharomyces cerevisiae fermentation product on heat stressed dairy cows". Journal of Dairy Science 103 (2020): 9634-9645.

9. Ruta L L., et al. "Saccharomyces cerevisiae cells lacking transcription factors Skn7 or Yap1 exhibit different susceptibility to cyanidin". Heliyon 6 (2020): 1-7.

10. Saito T L., et al. "SCMD: Saccharomyces cerevisiae Morphological Database". Nucleic Acids Research 32 (2004): D319-D322.

11. Reis V R., et al. "Characteristics of Saccharomyces cerevisiae yeasts exhibiting rough colonies and pseudohyphal morphol- ogy with respect to alcoholic fermentation". Brazilian Journal of Microbiology 44 (2013): 1121-1131.

12. Zakhartsev M and Reuss M. "Cellsize and morphological properties of yeast Saccharomyces cerevisiae in relation to growth temperature". FEMS Yeast Research 18 (2018): 1-16.

13. Tabanelli G., et al. "Survival of the functional yeast Kluyveromyces marxianus B0399 in fermented milk with added sorbic acid". Journal of Dairy Science 99 (2016): 120-129.

14. Mehmood N., et al. "Kluyveromyces marxianus, an attractive yeast for Ethanolic fermentation in the presence of imidazolium ionic liquids". International Journal of Molecular Sciences 19 (2018): 1-15.

15. Struyf N., et al. "Saccharomyces cerevisiae and Kluyveromyces marxianus cocultures allow reduction of fermentable oligo-, di-, and monosaccharides and polyols levels in whole wheat bread". Journal of Agricultural and Food Chemistry 65 (2017): 8704-8713.

16. Perpetuini G., et al. "Cell wall surface properties of Kluyveromyces marxianus strains from dairy products". Frontiers in Microbiology 10 (2019): 1-8.

\section{Assets from publication with us}

- Prompt Acknowledgement after receiving the article

- Thorough Double blinded peer review

- Rapid Publication

- Issue of Publication Certificate

- High visibility of your Published work

Website: www.actascientific.com/

Submit Article: www.actascientific.com/submission.php

Email us: editor@actascientific.com

Contact us: +919182824667 